九州大学学術情報リポジトリ

Kyushu University Institutional Repository

\title{
Variationi Characteristics of Meteorological Factors during Dust Storm at Dhunhuang, China
}

\section{Qui lang, Eduardo Jimmy Pua}

Laboratory of Applied Meteorology, Division of Regional Science, Department of Bioproductioin Environmental Sciences, Graduate School of Bioresource and Bioenvironmental Sciences, Kyushu University | Department of Earth Resources Science, National Institute of Agro-Environmental Sciences, Tsukuba

Maki, Taichi

Du, Mingyuan

Department of Earth Resources Science, National Institute of Agro-Environmental Sciences, Tsukuba

https://doi.org/10.5109/4636

出版情報: 九州大学大学院農学研究院紀要. 50 (1)，pp.189-199，2005-02-01. Faculty of Agriculture, Kyushu University バージョン :

権利関係 : 


\title{
Variation Characteristics of Meteorological Factors during Dust Storm at Dunhuang, China
}

\author{
Eduardo Jimmy Pua QUILANG ${ }^{1}$, Taichi MAKI* \\ and Mingyuan $\mathrm{DU}^{2}$
}

\begin{abstract}
Laboratory of Applied Meteorology, Division of Regional Environment Science, Department of Bioproduction Environmental Sciences, Faculty of Agriculture, Kyushu University, Fukuoka 812-8581, Japan

(Received November 4, 2004 and accepted November 11, 2004)
\end{abstract}

\begin{abstract}
Dunhuang as characterized during spring with considerable strong winds is one of the regions in China where an average of 14 dust storms per year occurs and passes. Agriculture, economy, human health and global climate are seriously affected by dust storms, which are the largest source of aerosols. Nowadays, satellites and numerical models track the intercontinental transport of dust particles.

To contribute in the data input, parameterization, and verification of a dust outbreak model, meteorological observations were started at Dunhuang in spring 2001. In this region, dust concentration index $(D C I)$ has been collected as a measure for dust concentration in the air. Likewise, meteorological parameters are being measured simultaneously.

Initial analyses of data from 2001 to 2004 showed that frequency of dust storm that passed by, originated from or settled down the station varied for each year. During dust storm, meteorological variations exhibited similar pattern, but wind speed and $D C I$ profiles depended on the type of dust storm. Furthermore, different relationships could be established between vertical properties $D C I$, wind speed, friction velocity, and roughness length. The most reliable being that $D C I$ and roughness length increases exponentially with strong wind speed (greater than $6 \mathrm{~m} / \mathrm{s}$ at $10 \mathrm{~m}$-level).

Further analyses including 2005 data are still needed to be more accurate and confident in establishing parameter relationships as inputs for the dust outbreak model.
\end{abstract}

\section{INTRODUCTION}

\section{Significance and background of the study}

Dunhuang is one of the main regions in China where a number of dust storms occurs and passes regularly. In this region, wind speeds are considerably strong which can stimulate dust storms. Du et al. (2002) reported that based on records, the average number of dust storms over the past 30 years (1961-1990) is about 14 times per year. These dust storms occur frequently during spring (From March to May) and sometimes even in summer, when strong wind blows on loosened dry ground with no surface vegetation.

Dust storms generated by wind (aeolian dust or yellow sand) cause serious damages to agriculture, economics and human health in arid and semiarid areas. Furthermore, it

\footnotetext{
' Laboratory of Applied Meteorology, Division of Regional Environment Science, Department of Bioproduction Environmental Sciences, Graduate School of Bioresources and Bioenvironmental Sciences, Kyushu University

2 Department of Earth Resources Science, National Institute of Agro-Environmental Sciences, Tsukuba

* Corresponding author (E-mail: maki@bpes.kyushu-u.ac.jp)
} 
has a great impact on global climate since it is the largest source of aerosols. The mineral dust particles change the radiative forcing of the atmosphere by scattering and absorbing short and long wave radiation. Dust scatter and absorb sunlight, as well as infrared light radiated by the Earth, which alters the radiation budget and is a major factor in studies of climate and climate change (Sokolik et al., 2001). They also have an indirect effect on the energy balance by altering the microphysics of clouds (Twomey, 1977; Hansen et al., 1998). It has long been clear that rainfall is the principal mechanism for cleansing the sky of dust, but only recently has the impact of dust on clouds been appreciated (Rosenfeld et al., 2001). Such effects may be widespread and not restricted to regions near deserts. Satellites and numerical models are now used to track the intercontinental transport of airborne particles.

During a dust storm, dust particles are suspended into the atmosphere and could be carried by wind over a very wide distance (Du et al., 2002a, b; Hedin and Likens, 1996). For example, dust generated in Taklimakan Desert, China can be transported to Japan (usually called Kosa) and even to the Pacific Ocean and North America.

According to researchers of the National Institute for Environmental Studies in Tsukuba, Ibaraki Prefecture, yellow sand from deserts in China and Mongolia each spring carries massive volumes of acid gases that can cause long-term soil depletion (The Japan times, 2001). The sand absorbs acid gases and carries them to foreign lands. Japan receives an estimated 1-3 million tons of such sand per year that may carry acid gas equivalent to the nitrogen oxide emitted from 350,000 to $1,050,000$ passenger cars. If the sand absorbs the gas, it would prevent acid rain but will cause long-term soil depletion. The sand itself is alkaline and is believed to have a neutralizing effect on acid rain.

Slight change in climate can cause a large difference in dust phenomena in the northwestern pacific region (Sugimoto et al., 2003). The same should be true to any dry area that occupy approximately half of the world's land surface and home to about 1 billion people. It therefore warrants a lot of attention from local, and international agencies. More work is needed on the important questions of monitoring, prediction, and forecasting of dust storms (Youlin et al., 2001). Hence, this study was undertaken.

\section{Objectives of the study}

There are a lot of studies that have been already conducted on desertification and aeolian dust, especially in China and Africa. Some studies focused only on investigation whereas others dealt with prevention of the problem. McTainsh (1999) and Shao (2001) reviewed long history of research literature on studies of dramatic dust transport and deposition. Although there had been some work on dust outbreak and emission (Garratt, 1984; Gilette et al., 1997), there are still some unknown features about surface conditions and dust outbreak (Du et al., 2002a, b) that need to be studied.

As a part of the Japan-China Cooperation Project on Aeolian Dust Experiment on Climate Impact (ADEC), continuous field observation of dust concentration and meteorological elements on different surfaces such as sandy desert and agricultural field were established. The project aims to obtain basic data to be used in dust outbreak modeling in the course of parameterization and verification. It also continues to elucidate the process of dust outbreak and its relationship with ground surface conditions, such as surface vegetation cover, soil water content, temperature, etc., This paper presents analyses of 
data obtained from Dunhuang springs 2001-2004, in relation to dust storm in sandy desert.

\section{Description of the site of the study}

Dunhuang is located west of Hexi Corridor of Gansu Province, China, to the north

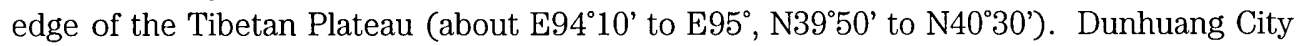
is very famous with a history of more than 1,000 years and for its Mogao Grottoes. The surface of this area is mainly Gobi and mountain. Oasis takes about $4.5 \%$ of the area. Annual precipitation is about $1982.7 \mathrm{~mm}$ and mainly distributed in the summer, from June to August (Wang, 1995). Annual air temperature is only about $9.3^{\circ} \mathrm{C}$ allowing for some snow even in summer. However, the daily and annual range of air temperature is very variable due to its dry condition and topography.

The station where the instruments were setup is a sandy desert or Gobi with particles of diameter $2-10 \mathrm{~mm}$ and located about $20 \mathrm{~km}$ from an oasis.

\section{MATERIALS AND METHODS}

\section{Observation system}

The observation system was introduced in detail by Du et al., (2003). Campbell Scientific (North Logan, Utah) weather systems were used and programmed to collect meteorological elements (wind speed $W s$, wind direction, air temperature, humidity, pressure, radiation, soil temperature and water content (TDR), heat flux, etc.). The station is a $10 \mathrm{~m}$ tower with 4 levels of wind, air temperature, and humidity observations, specifically at $1 \mathrm{~m}, 2 \mathrm{~m}, 4 \mathrm{~m}$ and $10 \mathrm{~m}$. Visibility was taken using Mira Visibility Sensor 3544.

\section{Observation method}

Meteorological elements were sampled every minute. Maximum and minimum wind speeds were also recorded. Data were imported into and analyzed in Microsoft Excel.

\section{Derivation of Dust Concentration Index}

Dust concentration index $(D C I)$ was derived from the visibility data with a slight modification of the equation

$$
m=A+B N+C N^{2}+D N^{3}
$$

where $m=$ visibility, $A=-0.5517, B=2.936, C=D=0$ and $N=$ raw data reading. This formula does not fit for dust because the visibility sensor was designed to detect fog and haze. However, based on previous data, visibility is directly proportional to dust concentration. Therefore, $D C I$ can be defined as:

$$
D C I=(a-N) / a,
$$

where $a=1,022$, the maximum raw data reading that the instrument can read when the sky is clear and there is no dust storm. Dust concentration index is between 0 (no dust event) and 1 (the most heavy dust event when visibility equals 0 ). 


\section{RESULTS AND DISCUSSION}

\section{Number of dust events per year}

Figure 1 shows that in Dunhuang, dust fluxes over four years at two different levels had behaved differently each year. This implies that the frequency of $D C I$ with values ranging from 0.6 to 0.9 , which are considered intense as mentioned by Du et al. (2002a, b) on the basis of observed dust particle counts also varied. The $D C I$ peaks can be seen either at high $(9 \mathrm{~m}$ or $10 \mathrm{~m})$ or low level $(2 \mathrm{~m}, 3 \mathrm{~m}$ or $4 \mathrm{~m})$, which could explain if dust storm had originated, passed, or settled at the region. It is interesting to note that dust events abruptly decreased in 2004. About seven intense events occurred in 2001, three for both 2002 and 2003, and only one in 2004. This can be explained by wind speed, which is the major cause of intense dust events. Wind speeds in 2004 were generally weaker compared to wind speeds in 2001. For example at $4 \mathrm{~m}$ height, maximum wind speed in 2004 was only $11.79 \mathrm{~m} / \mathrm{s}$ compared to $15.65 \mathrm{~m} / \mathrm{s}$ in 2001 . Another probable reason for greater number of strong events in 2001, is the fact that intense El Nino has occurred during this year resulting for the ground surface to be drier than other years.

This should be further investigated to determine some other factors that led to the decrease of dust events, like improved agricultural practices, established wind breaks, ground moisture, and rainfall. In Turpan, an arid land, and some parts around the Taklimakan Desert in Northwestern China, for example, meteorological improvement has been attributed to windbreaks and precipitation has been increasing and air temperature has been decreasing for 40 years due to the increase of development for agricultural fields (Maki et al., 2000).
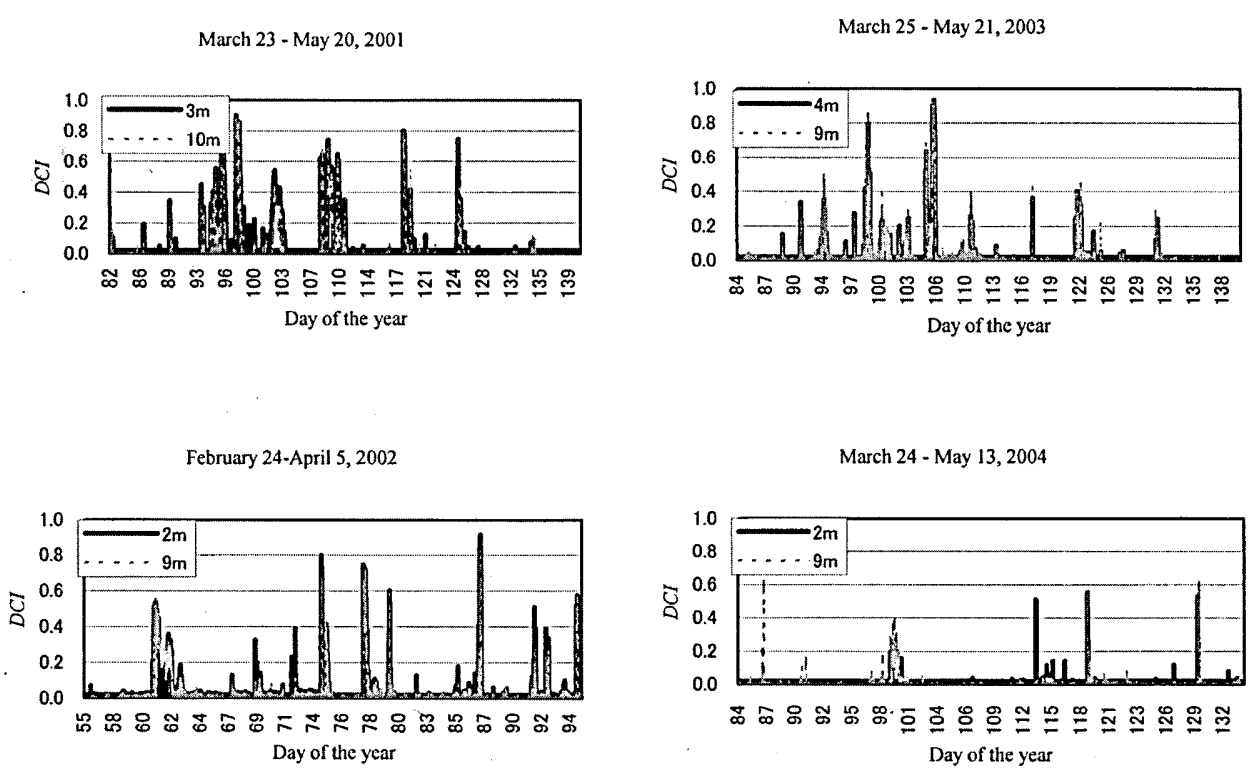

Fig. 1. Four-year dust storm concentration index in Dunhuang. 
Behavior of meteorological factors for each selected type of dust storm

Figures 2, 3 and 4 show the behavior of meteorological parameters during a selected dust event in different years. These dust events are unique from each other, the first one is a dust storm outbreak at the station, the second is a dust event that passed by at the station and the third one is a dust event that settled down at the station.

March 28, 2002
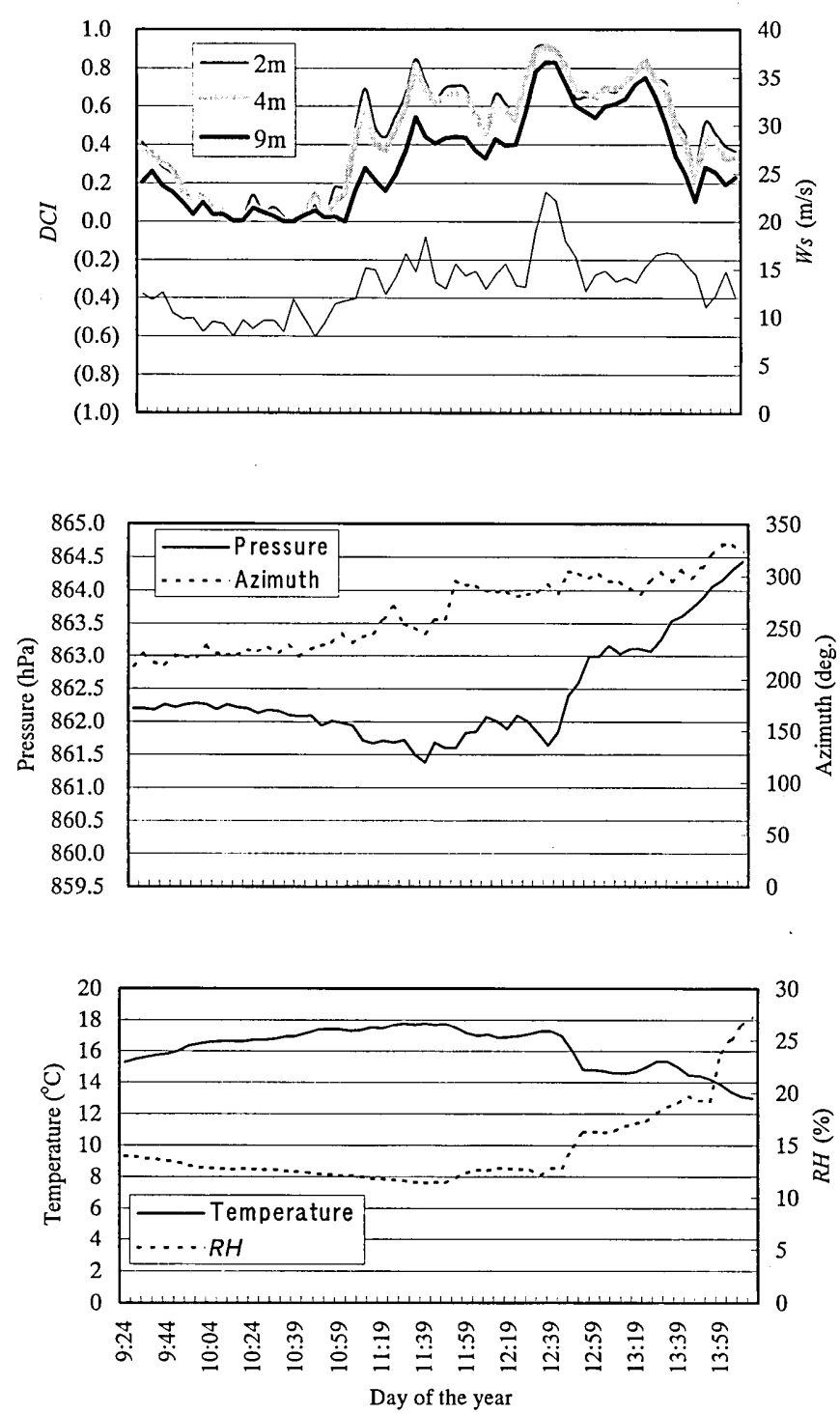

Fig. 2. Meteorological behavior of a selected typical dust storm outbreak at Dunhuang, China. 

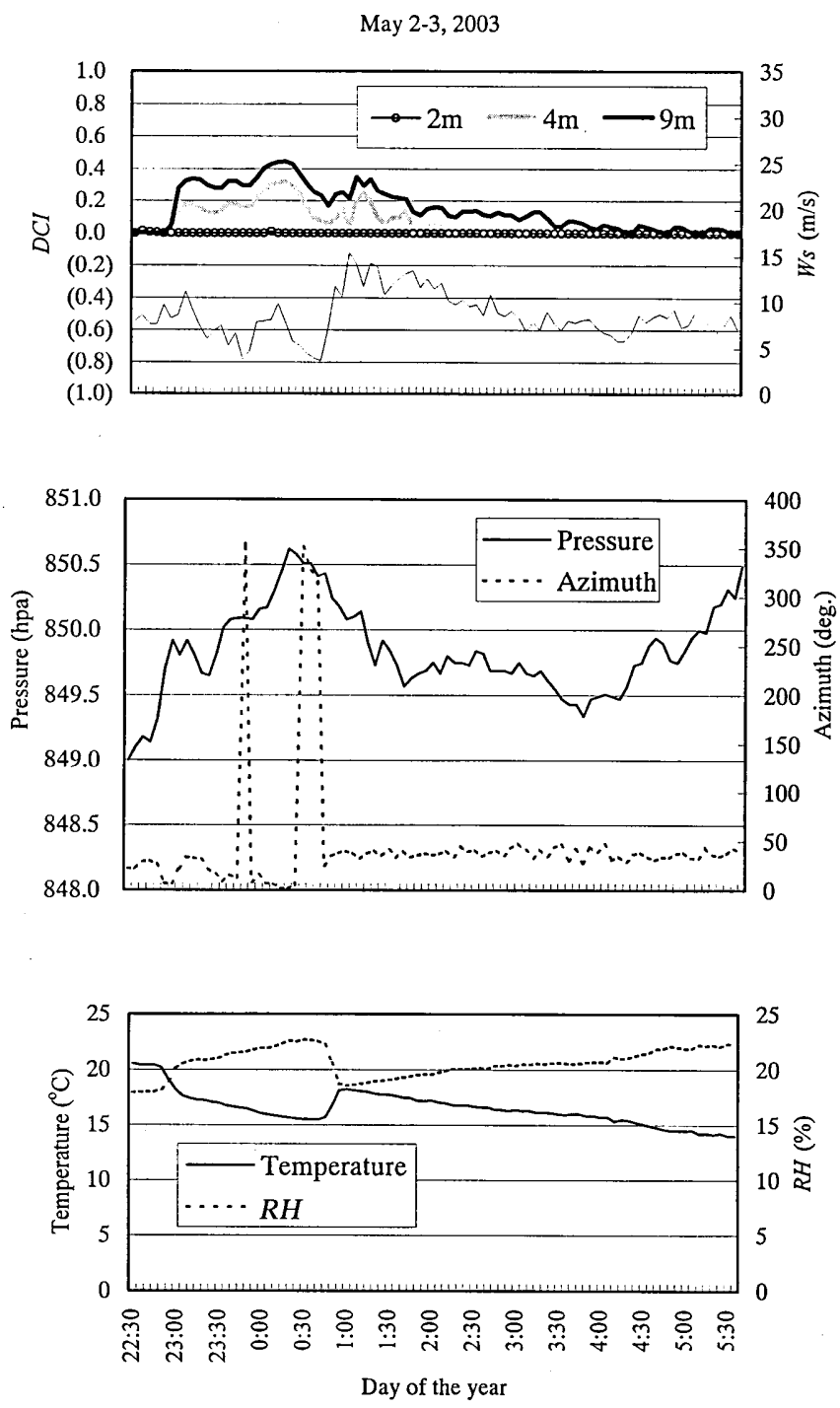

Fig. 3. Meteorological behavior of a selected dust storm that passed by Dunhuang, China.

In 2002 (Fig. 2), DCI reached 0.9 at the peak of the dust storm outbreak at either $2 \mathrm{~m}$ or $4 \mathrm{~m}$ with corresponding maximum wind speed of about $24 \mathrm{~m} / \mathrm{s}$. The $D C I$ fluxes at $2 \mathrm{~m}$ and $4 \mathrm{~m}$ were generally higher than those at $9 \mathrm{~m}$. This means that the event has occurred or started at the station itself because the dust particles accumulated first at the lower levels.

Before the dust storm, pressure was decreasing slowly, which then increased during 
and after the dust event. Wind speed increased with $D C I$ up to $24 \mathrm{~m} / \mathrm{s}$ with direction shifting from about $220^{\circ}$ (SW) to $325^{\circ}$ (NNW). Air temperature was inversely related to relative humidity from before, during and after the dust event outbreak. Temperature was increasing while relative humidity decreased before the event, and vice versa during, and even after the event. The same pattern was observed in 2001 for a selected dust storm outbreak (Du et al., 2002a, b).

Figure 3 was a suspected dust event that passed by because of the $D C I$ profile characteristic that shows higher fluxes at high level $(9 \mathrm{~m})$ than at low level $(4 \mathrm{~m})$ and no fluxes at $2 \mathrm{~m}$. Meteorological characteristic of this event in terms of wind speed and $D C I$ were low. The recorded maximum wind speed is only about $5 \mathrm{~m} / \mathrm{s}$ that coincided with maximum $D C I$ of 0.4 . These values suggest that this was not a dust storm that originated from the station. Instead, it could have been passing through the region. Or it may have originated from the oasis near the station, as was hinted by the higher $D C I$ values at $9 \mathrm{~m}$ than at $4 \mathrm{~m}$, which was extremely different from Fig. 2 . In this case, $D C I$ was inversely proportional with wind speed as exemplified from 23:00 to 1:00.

Furthermore, wind came from $25^{\circ}$ to $50^{\circ}$ (NNE) but suddenly changed in direction twice to $350^{\circ}$ (NNW) in the middle of 23:00 and 1:00. Pressure and $R H$ increased and temperature decreased when $D C I$ had increased. The same pattern was observed in Fig. 2 except for $D C I$ and wind speed behavior as explained earlier.

Figure 4 on the other hand was another case of dust event which was suspected to be a contributing dust deposition in the station owing to the $D C I$ profile characteristics that shows at the middle height with high fluxes and low at the lowest level.

Wind speed is low only $2 \mathrm{~m} / \mathrm{s}$ at the peak of $D C I 0.6$. Wind direction is erratic throughout this event changing from $0^{\circ}(\mathrm{N})$ to $360^{\circ}(\mathrm{N})$. Temperature and relative humidity are inversely related. Temperatures are low with negative values at the peak of $D C I$.

Du et al. (2002a, b) using 2001 data and Quilang et al. (2004) had previously discussed this common behavior of meteorological elements. Either it originated from or just passed by the station or region of Dunhuang. This behavior, especially the decrease in pressure (low pressure) before an event, is a peculiar observation when there is a forming thunderstorm.

Wind direction for each event as discussed was common at about $350^{\circ}$ (NNW). This information is indispensable in establishing a windbreak network to minimize dust events in Dunhuang, which are mostly generated by cold frontal systems with dry squall lines (Jakel, 2001).

Generally, weather conditions change severely before or after the transit of windstorms and sand-dust storms. Before the transit of sandstorms, the temperature is very high, air pressure is very low, weather is fine and wind velocity is low. When the sand-dust storms occur, strong wind sweep across, sand and dust flies upward, air pressure ascends immediately and air temperature drops suddenly (Youlin et al., 2001).

Overall, it was observed that there was no strong dust storm that occurred in Dunhuang in 2003 and 2004. Thus, no relationship between $D C I$ and wind speed could be observed. In contrast, an exponential relationship between the two parameters were derived in 2001 and 2002 which will be further discussed in the following section. 
March 2-3, 2002
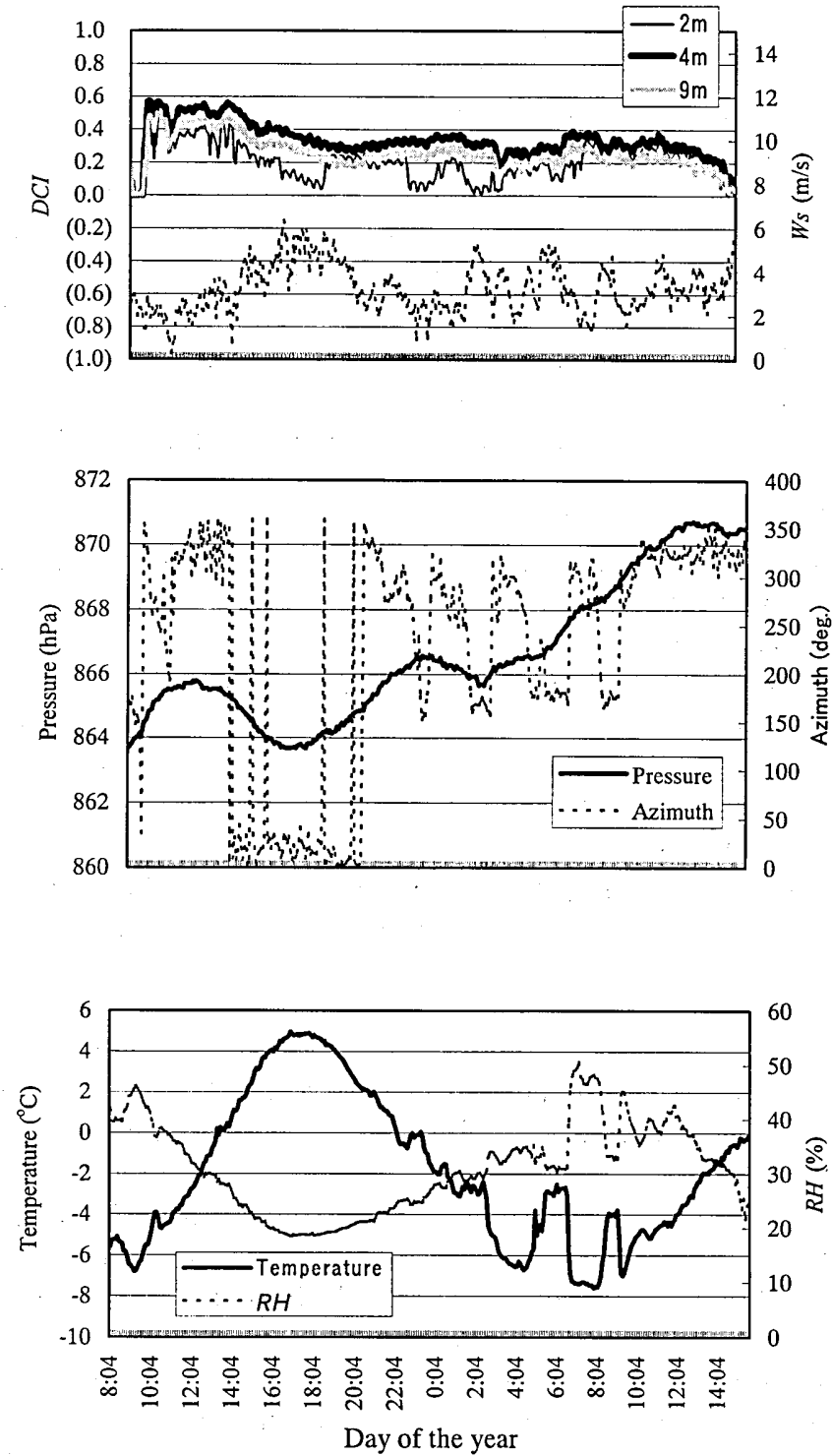

Fig. 4. A possible dust storm that settled down in Dunhuang, China. 
A

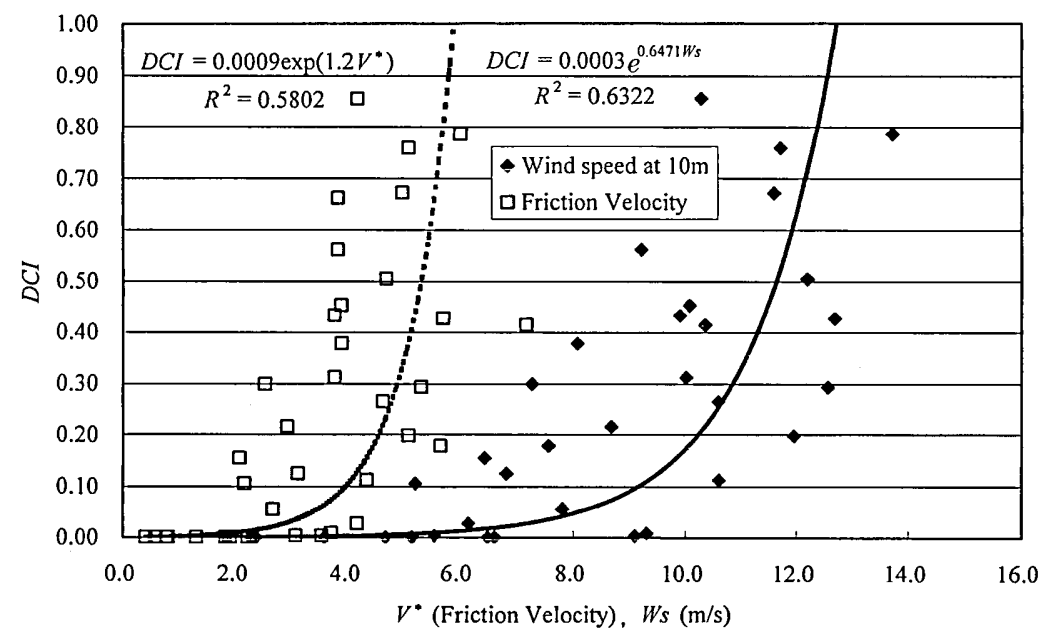

B

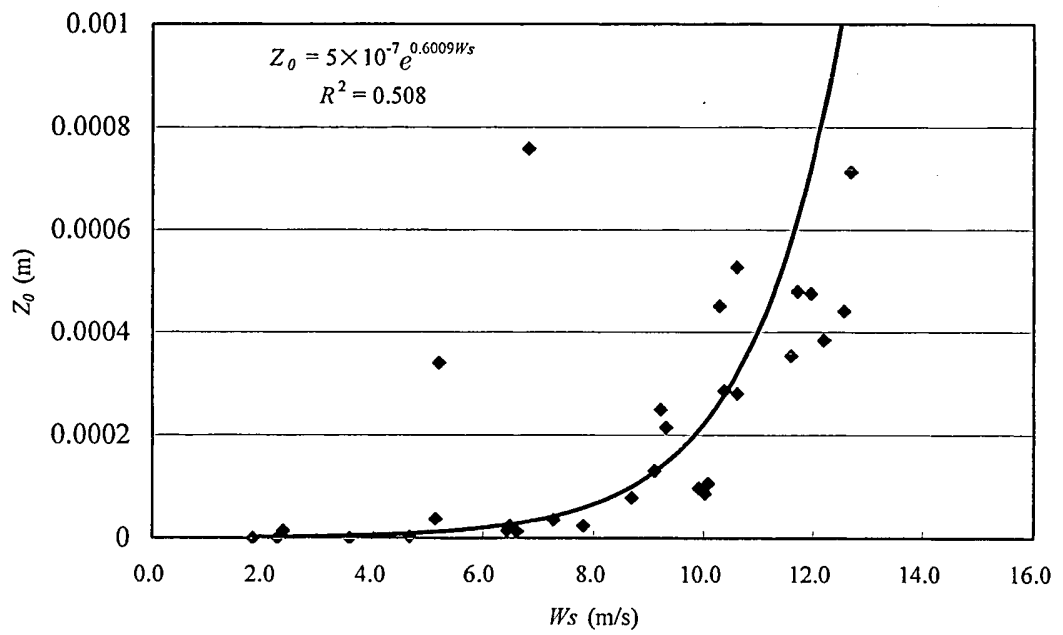

Fig. 5. Vertical properties $D C I$, wind speed, friction velocity and roughness length $\left(Z_{0}\right)$ relationships.

\section{Vertical properties relationship between Dust Concentration Index (DCI), wind speed (Ws), friction velocity $\left(V^{*}\right)$ and roughness length $\left(Z_{0}\right)$}

There are different possible relationships that can be obtained using Microsoft Excel scatter diagram trendline. These are linear, logarithmic, exponential and polynomial. The most reliable relationship between $D C I$, and wind speed is exponential with $R^{2}=$ 
0.6322 (Fig. 5A). Both, Maki et al. (2004) and Du et al. (2002a, b) also had a good discussion about this relationship. This was obtained when $D C I$ values were added with 0.001 as a correction factor. The best relationship was derived from the 2001 data. In 2002, exponential relationship was also observed but $R^{2}=0.3554$ only. In 2003 and 2004, no relationship was established because of weak wind speed and very low DCI. Figure $5 \mathrm{~A}$, also shows the relationship between friction velocity and $D C I$ that can be obtained with a reasonable $R^{2}=0.5802$. Since friction velocity is the square-root of the kinematic stress, these observations can easily be used to estimate stress. Close to the surface, friction velocity is not a function of height, which is very important in ocean and atmospheric modeling pur-poses. Observed friction velocity is a great advantage over wind because the dependence on atmospheric stability is (in theory) contained in the observation, and does not require an adjustment dependent on atmospheric stability (Bourassa et al., 1999).

On the other hand, due to saltation that occurred, roughness length change with wind speed exponentially as shown in Fig. 5B (Du et al., 2002b).

\section{SUMMARY, CONCLUSION AND RECOMMENDATION}

Dust storms had occurred with different frequency and intensity each year from 2001 to 2004. The frequency of intense dust storms with $0.6-0.9 \mathrm{DCI}$ has notably decreased. This decrease requires further investigation to know the factors that have caused this positive result. Windbreaks might have been established or anthropological activities like overgrazing became less.

Meteorological parameters displayed similar behaviors for each selected dust event for the last four years before, during, and after a dust storm except for $D C I$ and $W s$ characteristics.

An exponential relationship between $D C I$ and wind speed as well as friction velocity and roughness length were established using 2001 data. The other three-year (2002-2004) data did not give a good relationship because high $D C I$ values $(0.6-0.9)$ with corresponding strong wind speeds (greater than $6 \mathrm{~m} / \mathrm{s}$ and friction velocity over $1.6 \mathrm{~m} / \mathrm{s}$ ) were limited.

\section{ACKNOWLEDGEMENT}

The authors are grateful to the Ministry of Education, Culture, Sports, Science and Technology (MEXT) of the Japanese Government for the support provided through the Special Coordination Funds for Promoting Science and Technology.

\section{REFERENCES}

Bourassa, M. A., D. G. Vincent and W. L. Wood 1999 A flux parameterization including the effects of capillary waves and sea state. J. Atmos. Sci., 56: 1123-1139

Du, M., S. Yonemura, Z. Shen, Y. Shen, W. Wanfu and T. Maki 2002a Observation of the relationship between dust outbreak and ground surface conditions during dust events in Dunhuang, China. Proc. First ADEC workshop, January 17-18, pp. 4

$\mathrm{Du}$, M., S. Yonemura, Z. Shen, Y. Shen, W. Wanfu, and T. Maki 2002b Wind erosion processes during dust storm in Dunhuang, China. Proc. 12 $2^{\text {th }}$ International Soil Conservation Organization Conference, 
May 26-31, 624-629

Du, M., S. Yonemura, Z. Shen, Y. Shen, W. Wanfu and T. Maki 2003 Observational study of the relationship between ground surface condition and aeolian dust outbreak in Dunhuang, China. Arid Land Geography, 26: 25-31

Garratt, J. R. 1984 Cold fronts and dust storms during the Australian summer 1982-1983. Weather, 39: 98-103.

Gillette, D. A., E. Hardebeck and J. Parker 1997 Large-scale variability of wind erosion mass flux rate at Owens Lake 2: Role of roughness change, particle limitation, change of threshold friction velocity, and the Owen effect. J. Geophys. Res., 102: 25989-25998

Hansen, J., M. Sato, R. Ruedy, I. Tegen and E. Matthews 1998 Climate forcings in the industrial era. Proc. Natl. Acad. Sci., 95(12): 573-578

Hedin, L. O. and G. E. Likens 1996 Atmospheric dust and acid rain, Scientific American, 275(6): 56-60

Jakel, D. 2001 Causes of aeolian sand and dust transport in the deserts of China and in North Africa. Quarternary Sciences, 21(2): 172-182

Maki, T., M. Du, S. Yonemura, E. J. P. Quilang, Z. Shen, and W. Wang 2004 Blowing characteristics of dust or yellow sand from the land surfaces on a desert and oasis at Dunhuang in China. J. of Arid Land Studies, 14(2), 81-90 (in Japanese with English summary)

Maki, T. and M. Du 2000 Recent climatic change and micro-climatic alleviation by windbreaks in arid land of Northwestern China. J. of Arid Land Studies, 10S: 9-12

McTainsh, G. 1999 Dust transport and deposition. 181-212. In: Andrew S. Goudie, Ian Livingstone and Stephen Stokes (eds), Aeolian environments, sediments and landforms. John Wiley \& Son, LTD, pp. 325

Quilang, E. J. P., T. Maki and M. Du 2004 Behavior of meteorological parameters during dust storm in Dunhuang, China. Proc. of the Jap. Asso. for Arid Land Studies, 53-54

Rosenfeld, D., Y. Rudich and R. Lahav 2001 Desert dust suppressing precipitation: A possible desertification feedback loop. Proc. Natl Acad. Sci., USA, 98(11): 5975-5980

Shao, Y. 2001: Physics and modeling of wind erosion, pp. 393

Sokolik, I. N., D. M. Winker, G. Bergametti, D. A. Gillette, G. Carmichael, Y. J. Kaufman, L. Gomes, L. Schuetz and J. E. Penner 2001 Introduction to special section: Outstanding problems in quantifying the radiative impacts of mineral dust, J. Geophys. Res., 106: 18015-18027

Sugimoto, N., I. Uno, M. Nishikawa, A. Shimizu, I. Matsui, X. Dong, Y. Chen and H. Quan 2003 Record of heavy Asian dust in Beijing in 2002. Geophysical Research Letters, 30(12): 1640

The Japan Times on Line., October 1, 2001 Soil depletion feared, foreign sand spreading acid. http:/www.japantimes.co.jp/cgi-bin/getarticle.pl5?nn20011001a3.htm

Twomey, S. 1977 The influence of pollution on shortwave albedo of clouds. J. Atmos. Sci., 34: 1149-1152

Wang, S., D. Yang, T. Jin and Q. Xu 1995 Distribution of dust storm in Nortwestern China and their causes. In Resources exploitation, global change and sustainable development, the resources and environment issue of the proceedings of the second academic conference of young scientists of China. China Association for Science and Technology Press, Beijing, China, 364-370

Youlin, Y., V. Squires and L. Qi 2001 In Introduction: Global Alarm: Dust and Sandstorms From the World`s Drylands. UNCCD, UNEP, UNESCO, FAO, and ESCAP, 7-8, 32

Zhang, X., R. Arimoto and Z. An 1997 Dust emission from Chinese desert sources linked to variations in atmospheric circulation. J. Geophys. Res., 102(D23): 28041-28047 